\title{
Transcranial color-coded Doppler ultrasonography for evaluation of children with hydrocephalus
}

\author{
Ricardo Santos de Oliveira, M.D., Ph.D., and Hélio Rubens Machado, M.D., Ph.D. \\ Department of Surgery and Anatomy, Division of Pediatric Neurosurgery, Hospital of Clinics, Faculty \\ of Medicine Ribeirao Preto, University of Sao Paulo, Brazil
}

\begin{abstract}
Object. Hydrocephalus is a common disease process. Transcranial color-coded Doppler (TCCD) ultrasonography is an accepted noninvasive method with which to quantify intracranial blood flow in adults and children. The authors studied the applications of TCCD ultrasonography and the alterations of the flow velocity of the cerebral arteries in children with hydrocephalus.

Methods. One hundred thirty-five children were divided into three groups: Group 1 comprised 40 infants with asymptomatic hydrocephalus who had well-functioning ventriculoperitoneal (VP) shunts; Group 2 comprised 10 children with symptomatic hydrocephalus who had malfunctioning shunts that were replaced; and Group 3 was a control group of 85 healthy infants. All patients underwent sequential measurements of cerebral blood flow (CBF) velocities (systolic and diastolic velocities) and resistivity index (RI). One group of patients underwent functional tests (compression of the anterior fontanelle and $\mathrm{CO}_{2}$ vasoreactivity) to determine hemodynamic changes in cerebral circulation.

A significant statistical change in RI measurements, end diastolic CBF velocity, and percentage of change in RI was shown in patients with malfunctioning shunts, and in infants with a well-functioning VP shunt vasomotor reactivity was severely reduced.

Conclusions. Transcranial color-coded Doppler ultrasonography can be used to perform follow-up assessments of normal and malfunctioning shunts in children with hydrocephalus; the functional tests are a noninvasive tool for evaluating the cerebral compliance and the cerebral autoregulation in infants with hydrocephalus. The autoregulatory capacity may partly or completely be lost in cases of long-term shunt-treated hydrocephalus, and loss of cerebral vasoreactivity may be responsible for long-term deficits commonly observed in children, which help explain some of symptoms related to slit ventricles.
\end{abstract}

\section{KEY WORDS - transcranial Doppler ultrasonography • hydrocephalus • ventriculoperitoneal shunt - carbon dioxide vasoreactivity}

The introduction of TCD ultrasonography by Aaslid, et al., ${ }^{2}$ in 1982 offered a portable, noninvasive means for measuring $\mathrm{CBF}$ velocity in the major intracranial vessels. Therefore, applications of this new technology increased considerably and included use in infants and children with hydrocephalus. The Pourcelot $\mathrm{RI}^{22}$ and the Gosling $\mathrm{PI}^{13}$ are the two most commonly used PIs in patients with hydrocephalus. Both were initially used to study cerebral circulation in hydrocephalus in $1982 .{ }^{15}$

Cerebral TCCD ultrasonography, first performed in $1989,{ }^{27}$ allows direct visualization at basal cerebral arteries and demonstrates CBF easily because of the color coding. ${ }^{6,7}$

Abbreviations used in this paper: $\mathrm{ACA}=$ anterior cerebral artery; $\mathrm{CBF}=$ cerebral blood flow; $\mathrm{CNS}=$ central nervous system; $\mathrm{CT}=$ computerized tomography; ICA = internal carotid artery; ICP = intracranial pressure; $\mathrm{MCA}=$ middle cerebral artery; $\mathrm{MR}=$ magnetic resonance; $\mathrm{PCA}=$ posterior cerebral artery; $\mathrm{PI}=$ pulsatility index; RI = resistivity index; $\mathrm{SD}=$ standard deviation; $\mathrm{TCD}=$ transcranial Doppler; TCCD = transcranial color-coded Doppler; $\mathrm{VP}=$ ventriculoperitoneal.
In infants, because both the anterior fontanelle and the temporal bone window can be used to assess the cerebral circulation, the circle of Willis arteries (the ACA, MCA, ICA, and PCA) can be easily insonated. ${ }^{7}$

The purpose of our study was to determine prospectively how RI and velocity measurements, obtained using TCCD ultrasonography, are affected in children with long-term asymptomatic or malfunctioning shunts. To define better the CBF hemodynamic changes in hydrocephalus, functional tests (RI changes in response to fontanelle compression and to $\mathrm{CO}_{2}$-inhaled vasomotor reactivity) were performed.

\section{CLINICAL MATERIAL AND METHODS}

This study was performed in accordance with the ethical standards established by the ethics committee at our institution.

A single-institution prospective cohort study was conducted to compare the outcomes in children with hydrocephalus who had functioning and malfunctioning shunts 
and the applications of TCCD ultrasonography in selected cases. All patients presented to the pediatric neurosurgery section of our institution between February 1999 and June 2000. The patients exhibited no signs or symptoms suggestive of cardiac or respiratory problems, and analysis of hematopoiesis of peripheral blood showed normal findings.

Fifty pediatric and young-adult patients were studied (newborn-18 years of age); in all patients VP shunts had been placed to treat hydrocephalus. Congenital hydrocephalus was documented in 35 patients and acquired hydrocephalus in 15, based on clinical presentation and imaging studies (real-time ultrasonography, CT scanning, or MR imaging). The cases of neoplasm-induced hydrocephalus were excluded. The control group was composed of 85 healthy children.

We divided the 135 children into three groups: Group 1 comprised 40 asymptomatic children with a good functioning VP shunt that had not required revision for at least 2 years; Group 2 was made up of 10 symptomatic children with malfunctioning shunts that had required surgical revision; and Group 3 was composed of 85 healthy infants who served as the control population and in whom CNS disease was absent. The normal range of $\mathrm{CBF}$ velocities was determined, and sequential measurements of intracranial arterial blood flow velocities were measured (systolic velocity, end diastolic velocity, and RI).

The RI was calculated by dividing the difference between peak systolic and end diastolic velocity values by peak systolic measurement $(\mathrm{RI}=$ peak systolic velocity end diastolic velocity/peak systolic velocity). The RI is a ratio and can be expressed in whole numbers, percentages, or a fraction to minimize the error in estimating the true velocity as a result of a varying angles of insonation.

The patients underwent real-time TCCD ultrasonography assessment of basal cranial arteries (model HDI 3000 or HDI 5000; Advanced Technology Laboratories, Inc., Bothell, WA) equipped with a 2 to $4-\mathrm{MHz}$ transcranial phased-array transducer and/or 4 to 7-MHz transfontanellar phased-array transducer.

In Group 1, we evaluated CBF velocity by insonation of the MCA, ICA, and PCA through the temporal squama. The arteries evaluated in Groups 2 and 3 were the ACA, MCA, ICA, and PCA; assessment was performed through the temporal squama and/or the anterior fontanelle in all patients in whom this acoustic window existed.

The TCCD ultrasonography sample size and the wall filter were set at their lowest levels, and the pulse repetition frequency (velocity scale) and baseline were adjusted to display a spectral waveform optimally over the full height of the scale, without risk of creating an "alias." After a stable waveform was obtained over at least $5 \mathrm{sec}$ onds, the image was captured, and the RI in the arteries was determined, with cursors identifying the peak systolic and end diastolic velocities in a standard fashion. Angle correction was not undertaken.

A group of patients underwent functional testing to evaluate hemodynamic changes of cerebral circulation. These tests consisted of the response to fontanelle compression and analysis of vasomotor reactivity after inhalation of $\mathrm{CO}_{2}$ and spontaneous hyperventilation.

The compression of the anterior fontanelle during TCD ultrasonography examination of the ACA was performed in 10 pediatric patients with malfunctioning shunts before and after surgery (Group 2); this consisted of the transducer-applied uniform continuous pressure through the acoustic window in a period of fewer than 5 seconds. The ACA or its pericallosal branch was identified in the midsagittal plane, and this vessel was subsequently insonated at its vertical course, immediately anterior to the genu of the corpus callosum. All RIs, percent of change in RIs, and peak systolic and end diastolic velocities were obtained from each spectrum and recorded (Fig. 1).

Percentage of change in RI was defined as the following: (fontanelle compression RI - baseline RI)/baseline RI.

The instant effects of pressure application and release on the Doppler spectral waveform were also documented during each study. The amount of pressure was made uniform subjectively among patients by having one examiner performing all TCCD ultrasonography studies, but no attempt was made to quantify or monitor pressure application. Fifteen healthy infants also underwent this test (Group 3 [control patients]).

Ten Group 1 infants with functioning asymptomatic shunts underwent Doppler $\mathrm{CO}_{2}$ testing. The patients inhaled normal air at rest and a gas mixture of air and $\mathrm{CO}_{2}$ $(5 \%)$ through a mouthpiece connected to a reservoir in hypercapnia phase and, after this, a phase of voluntary increased hyperventilation (hypocapnia). The $\mathrm{M}_{1}$ segment of the MCA and $\mathrm{P}_{1}$ segment of the PCA were studied with TCCD ultrasonography performed through the temporal

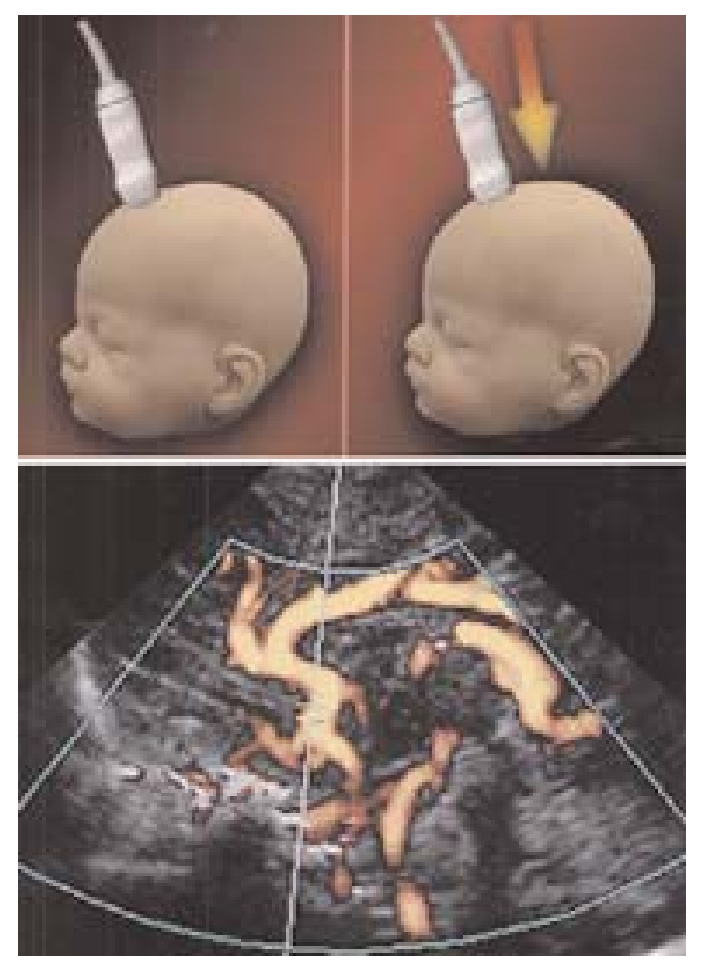

Fig. 1. Upper: Fontanelle compression test. The transducer is placed in contact with the anterior fontanelle, and uniform continuous pressure with the transducer is applied by the operator through this acoustic window. Lower: Sagittal TCCD ultrasonography demonstrating color coding of the ACA. 
squama, and measurements of the mean velocity were calculated, and values were expressed by percentage of vasomotor reactivity $\left(\mathrm{CO}_{2} \mathrm{RI}\right)$. The $\mathrm{CO}_{2} \mathrm{RI}$ was calculated using the following formula: ${ }^{24}$ where $\mathrm{V} 1$ is the baseline flow velocity, $\mathrm{V} 2$ is the final flow velocity after $\mathrm{CO}_{2}$ administration, and V3 is the final flow velocity after hyperventilation.

All TCCD ultrasonography measurements are represented as mean velocities.

Ten Group 3 infants without CNS disease also underwent TCCD ultrasonography testing. In some cases, not all vessels could be insonated; the mean values for all vessels studied were calculated in each patient and the RI was calculated to the nearest percentage, and systolic and diastolic flow velocities in centimeters per second.

The values for each group are presented as the mean \pm 1 SD. Data were analyzed using the multivariate Wilcoxon test for comparison of two samples used to define the association among the groups and within each group. A probability value less than 0.05 was used as the significance level.

\section{RESULTS}

The RI values determined in the different groups are summarized in Table 1.

In Group 140 TCCD ultrasonography examinations were performed in 40 patients. The Doppler sign was obtained in $181(75.4 \%)$ of 240 intracranial arteries. Sequential CT scanning or MR imaging revealed normalsized ventricles in 20 patients $(50 \%)$, slit ventricles in 15 $(37.5 \%)$, and dilated ventricles in five $(12.5 \%)$.

During the period of this study, the VP shunt malfunctioned in two patients who underwent TCCD ultrasonography assessment on three occasions (when they were asymptomatic, during the malfunction, and after the shunt was changed). The results are presented in Fig. 2.

In Group 2, the mean RI value was $62 \pm 5 \%$. Following shunt revision in these patients, the mean RI decreased to $50 \pm 5 \%(\mathrm{p}<0.05)$. The RI in association with clinical status is presented in Table 2 .

Anterior fontanelle compression produced a significant statistical change in RI measurements, end diastolic flow velocity, and percentage of change in RI in infants with malfunctioning shunts.

The end diastolic flow velocity decreased significantly before surgery $(\mathrm{p}<0.001)$ to $30.9 \pm 12 \mathrm{~cm} /$ second $(10$ paired observations) and, with fontanelle compression, to $13.7 \pm 9 \mathrm{~cm} / \mathrm{second}$. Before treatment, the mean RI with

TABLE 1

Correlation of RI values and clinical status in three groups of pediatric patients

\begin{tabular}{cccc}
\hline \hline Group No. & $\begin{array}{c}\text { No. of } \\
\text { Cases }\end{array}$ & Clinical Status & $\begin{array}{c}\text { Mean RI } \\
\pm 1 \text { SD (\%) }\end{array}$ \\
\hline 1 & 40 & $\begin{array}{c}\text { functional shunt; } \\
\text { asymptomatic } \\
\text { symptomatic shunt } \\
\text { before revision } \\
\text { after revision }\end{array}$ & $52 \pm 6$ \\
& 10 & no shunts or CNS disease & $62 \pm 5$ \\
3 & 85 & & $50 \pm 5$ \\
\hline
\end{tabular}

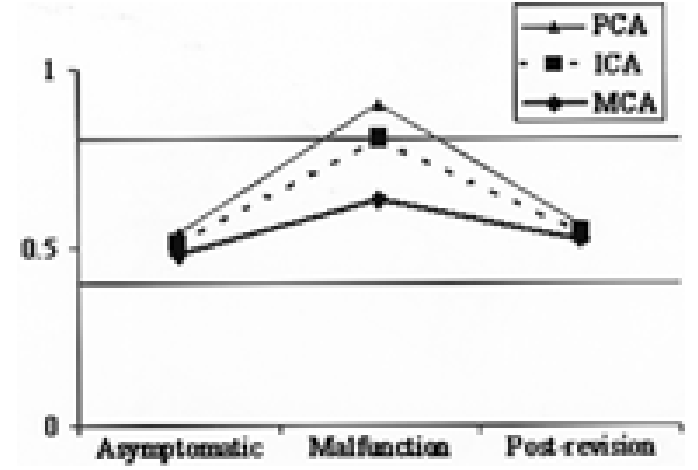

Fig. 2. Graph demonstrating RI changes in the MCA, ICA, and PCA in two Group 1 patients examined prior to shunt malfunction, at the time of shunt malfunction, and after revision surgery. We identified an increase in RI that occurred from baseline when the shunt failed.

fontanelle compression increased significantly $(\mathrm{p}<$ 0.001 ) in patients with malfunctioning shunts to $60 \pm 9 \%$ and with fontanelle compression to $80 \pm 10 \%$. The percentage of change in RI decreased significantly $(\mathrm{p}<$ $0.0001)$ to $24.3 \pm 10 \%$ in patients with malfunctioning shunts and after the surgical treatment to $6.4 \pm 5 \%$. The values of peak systolic velocity did not change significantly with fontanelle compression before and after surgical change of the shunt $(\mathrm{p}>0.05)$. Compared with the control group, the values of peak systolic velocity prior to surgical revision were significantly increased $(\mathrm{p}<0.001)$. The results are summarized in Fig. 3 and Table 3.

In Group 1, 10 infants with asymptomatic shunts underwent Doppler $\mathrm{CO}_{2}$ testing. Routine sequential CT scanning performed after shunt implantation demonstrated typical slit ventricles in eight cases. Severely reduced vasomotor reactivity was demonstrated in patients with long-term shunts and in asymptomatic patients compared with the control group (Figs. 4-6).

\section{DISCUSSION}

Considerable improvements in the treatment of childhood hydrocephalus have been demonstrated. Although medical care and shunt-related technology may be responsible for better outcome, ${ }^{16,26,31}$ neuroimaging studies have

TABLE 2

Anterior cerebral artery-based RI values in relation to fontanelle compression testing

\begin{tabular}{|c|c|c|c|c|c|c|}
\hline \multirow[b]{3}{*}{ Group } & \multicolumn{5}{|c|}{ Fontanelle Compression Test } & \\
\hline & \multicolumn{3}{|c|}{ Not Performed } & \multicolumn{3}{|c|}{ Performed } \\
\hline & $\begin{array}{l}\text { No. of } \\
\text { Cases }\end{array}$ & $\mathrm{RI}(\%)^{*}$ & $\begin{array}{c}\text { Range } \\
(\%)\end{array}$ & $\begin{array}{l}\text { No. of } \\
\text { Cases }\end{array}$ & $\mathrm{RI}(\%)^{*}$ & $\begin{array}{c}\text { Range } \\
(\%)\end{array}$ \\
\hline study group & 10 & & & 10 & & \\
\hline preop & & $62 \pm 5$ & $50-78$ & & $80 \pm 10$ & $68-100$ \\
\hline postop & & $50 \pm 10$ & $47-70$ & & $60 \pm 14$ & $41-78$ \\
\hline control group & 15 & $60 \pm 9$ & $53-77$ & 15 & $70 \pm 12$ & $52-77$ \\
\hline
\end{tabular}

$*$ Values are presented as the means \pm SDs. 


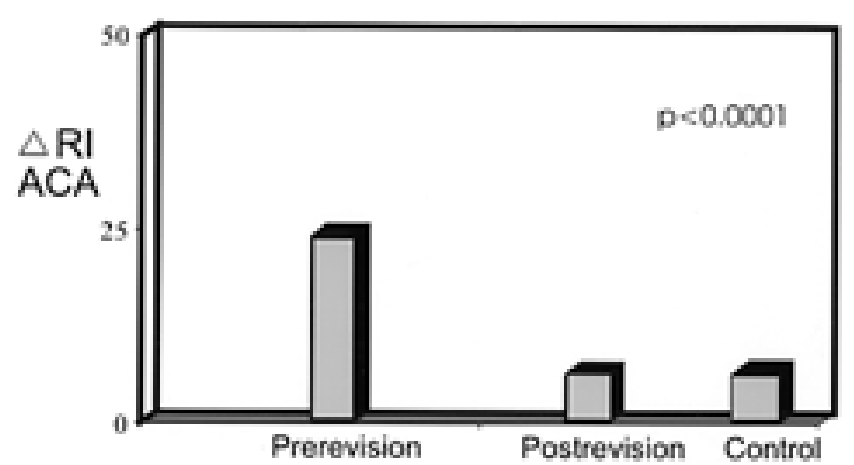

Fig. 3. Bar graph demonstrating graphically the percentage of change in RI ( $\Delta \mathrm{RI})$ in the ACA demonstrated in 10 Group 2 patients with malfunctioning shunts, undergoing fontanelle compression testing before after revision. A significant increase in percentage of change in RI occurred before revision. Values obtained in the control patients are presented for comparison.

certainly had a great impact on diagnostic and follow-up evaluation in this population. Early diagnosis allows proper indication of whether surgery should be performed, both initially and after development of complications in patients with malfunctioning shunts, thus preventing future cognitive deterioration. ${ }^{12}$

Computerized tomography scanning and MR imaging have completely changed our concepts in pediatric neurosurgery. Although these modalities are necessary in evaluating children with hydrocephalus, their indications should be carefully monitored both from economic and medical points of view. Irradiation of an incompletely myelinated brain and even the whole body is burdensome in children; it is not rare that an infant has undergone a dozen or more CT scanning studies when shunt malfunctioning is suspected. Although not radiation based, MR imaging requires sedation and its costs are considerable; additionally, it is not always available in busy neurosurgical centers. ${ }^{18}$

The addition of TCD technology to ultrasonographic examination made it possible to conduct studies in children after fontanelle closure, by applying the transducer to the temporal region. ${ }^{20,25,28,36}$ The use of TCD allows one to obtain real-time measurements of arterial or venous blood flow velocity directly from insonation of vessels coded in

TABLE 3

Anterior cerebral artery-based end diastolic velocity values in relation to fontanelle compression testing

\begin{tabular}{|c|c|c|c|c|c|c|}
\hline \multirow[b]{3}{*}{ Group } & \multicolumn{5}{|c|}{ Fontanelle Compression Test } & \\
\hline & \multicolumn{3}{|c|}{ Not Performed } & \multicolumn{3}{|c|}{ Performed } \\
\hline & $\begin{array}{l}\text { No. of } \\
\text { Cases }\end{array}$ & $\begin{array}{l}\text { End Dia- } \\
\text { stolic*广† }\end{array}$ & Range $^{\dagger}$ & $\begin{array}{l}\text { No. of } \\
\text { Cases }\end{array}$ & $\begin{array}{l}\text { End Dia- } \\
\text { stolic* }{ }^{\dagger}\end{array}$ & Range ${ }^{\dagger}$ \\
\hline study group & 10 & & & 10 & & \\
\hline preop & & $31 \pm 12$ & $16-35$ & & $13.7 \pm 9$ & $0-25$ \\
\hline postop & & $27 \pm 11$ & $9-48$ & & $28 \pm 12$ & $7-40$ \\
\hline control group & 15 & $22 \pm 11$ & $9-36$ & 15 & $19 \pm 10$ & $11-47$ \\
\hline
\end{tabular}

* Values are expressed as the means \pm SDs.

$\dagger$ Values are presented in centimeters/second.
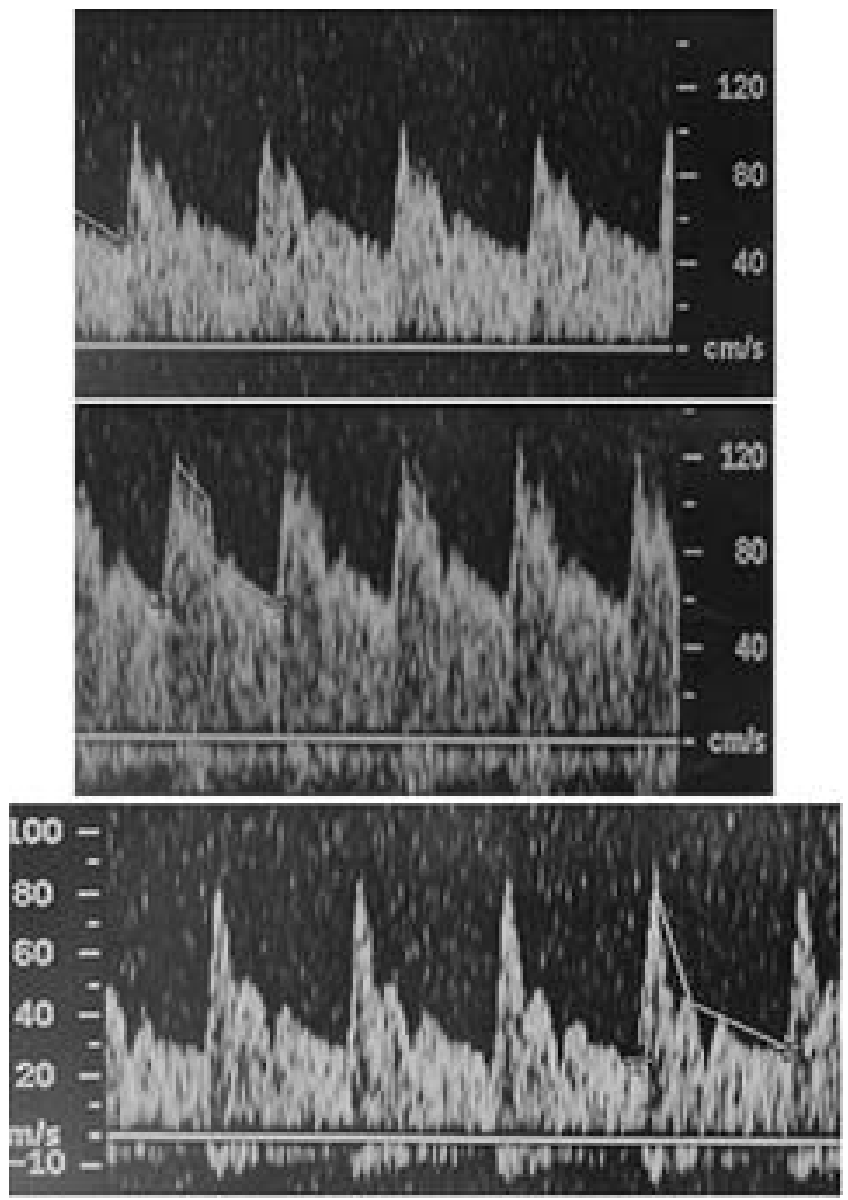

Fig. 4. Normal findings obtained during $\mathrm{CO}_{2}$ testing. Effects are shown for Doppler spectrum of the cerebrovascular reactivity measured in the MCA of a normal infant (vasomotor reactivity $70 \%$ ) undergoing $\mathrm{CO}_{2}$ testing in normoventilation (upper), hypoventilation (center), and hyperventilation (lower).

color or by methodically searching the vessels and analyzing changes in sound frequencies. ${ }^{2,5}$

Although direct measurement of the ICP remains the gold standard for determining the adequacy of ventricular decompression at any particular moment, such procedures are invasive. . $^{819,23}$

Transcranial color-coded Doppler ultrasonography allows rapid, noninvasive assessment of blood flow velocities in the major intracranial vessels and can be performed repeatedly. Since the introduction of TCD ultrasonography, several authors have described the relationship between raised ICP and the Doppler waveform. This waveform has been expressed by several indices, such as the PI and the RI. These indices are used to demonstrate the presence of raised ICP. ${ }^{29}$ The authors of previous studies have reported good correlation between RI and raised ICP in cases involving various intracranial pathological processes including hydrocephalus. . $^{30,37}$

The elevation of RI with ICP is related to impaired diastolic blood flow. In infants with malfunctioning shunts, the TCCD ultrasonography measurement-identification elevation of RI is presumed to reflect elevated ICP..$^{19,21,33}$ 

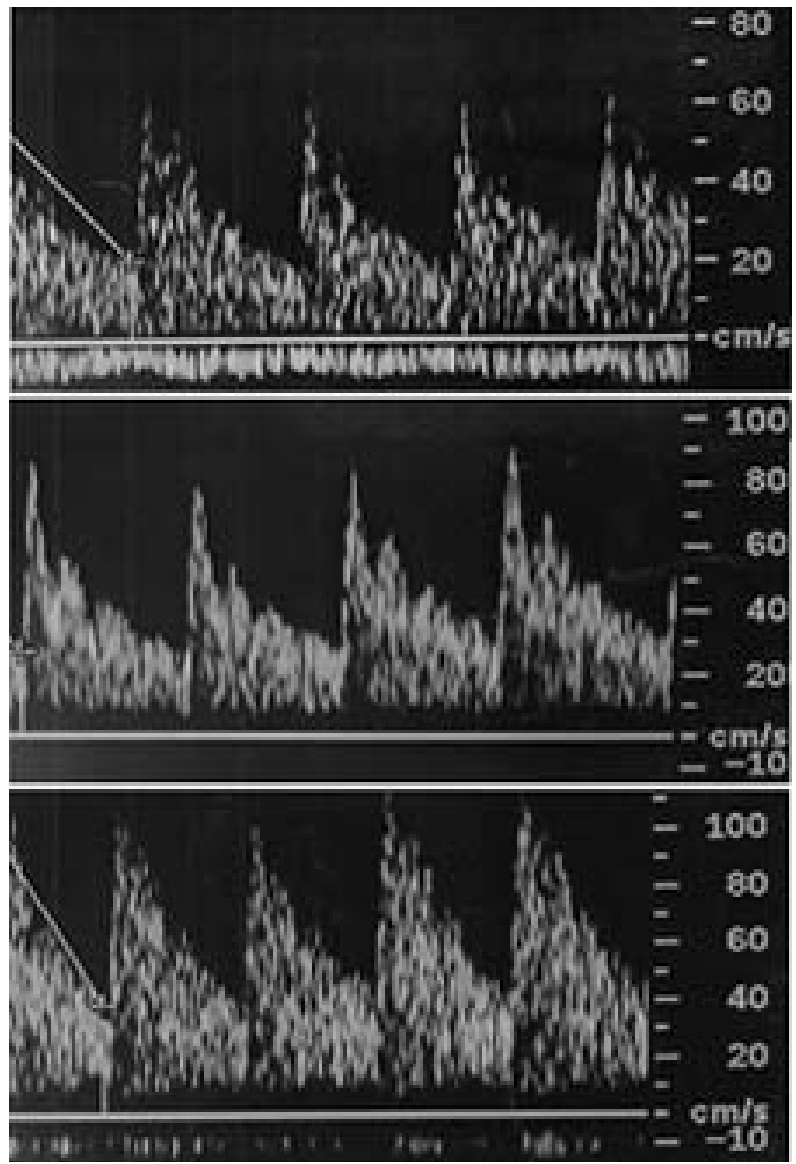

Fig. 5. Representive findings of cerebrovascular reactivity studies measured in the MCA of a Group 1 infant (vasomotor reactivity $40 \%$ ) undergoing $\mathrm{CO}_{2}$ testing in normoventilation (upper), hypoventilation (center), and hyperventilation (lower). Results indicated a severely reduced vasomotor reactivity in patients with hydrocephalus and a functional shunt.

There are many factors that influence the RI such as cardiac output, heart rate, presence of a ductus arteriosus, and the use of vasoactive medications such as dopamine. Some authors have reported finding no statistical relationship between RI and ICP, but in these studies the investi- gators used measurements for RI without fontanelle compression. ${ }^{3,14}$ In the present study the patients underwent clinical and laboratory evaluation before TCCD ultrasonography measurements were obtained.

In children with hydrocephalus treated using shunt therapy the use of functional tests to evaluate normal and pathological postoperative courses improves the sensitivity, specificity, and accuracy of establishing the presence of raised ICP and its correlation with RI. ${ }^{34}$

Compression of the fontanelle produces a transient increase of intracranial volume and is presumed to be a noninvasive predictor of altered cerebral compliance in children with ventricular dilation. This method is useful, noninvasive, and well tolerated by children. The presence of reversed blood flow during diastole demonstrated on TCCD ultrasonography during the fontanelle compression is strongly suggestive of elevated ICP. ${ }^{32}$

We found that in Group 1 patients, RI values were nor$\mathrm{mal}$; however, two patients in this group presented with malfunctioning shunts. Baseline RI values were very important because after the shunt was revised, we observed normal RI values. The use of TCCD ultrasonography in regular follow-up evaluation helped us to determine the optimal time for shunt revision. Similar results have been demonstrated by other authors in patients with malfunctioning shunts. ${ }^{8}$

In Group 2, transfontanellar color Doppler ultrasonography in association with the fontanelle compression test demonstrated increased RI $(\mathrm{p}<0.001)$ and percentage of change in RI $(p<0.0001)$ before surgical revision of any shunt, and we observed significantly decreased end diastolic velocity after the fontanelle compression test $(\mathrm{p}<$ $0.001)$. In some cases, reverse diastolic flow occurred after fontanelle compression. When this test was performed in 15 healthy infants without CNS disease, no significant increase in RI, end diastolic velocity, or percentage of change in RI was demonstrated.

To evaluate the effects of long-term shunt therapy in asymptomatic children with hydrocephalus, 10 of the Group 1 children underwent Doppler $\mathrm{CO}_{2}$ testing. ${ }^{24} \mathrm{Va}-$ somotor reactivity in healthy individuals has been defined previously. ${ }^{24}$ Any $\mathrm{CO}_{2}$-induced blood flow velocity changes differed for hyper- and hypocapnia. The degrees of vasomotor reactivity are severe reduction $(\leq 33 \%)$, moderate reduction $(34-64 \%)$, and normal $(\geq 65 \%)$.
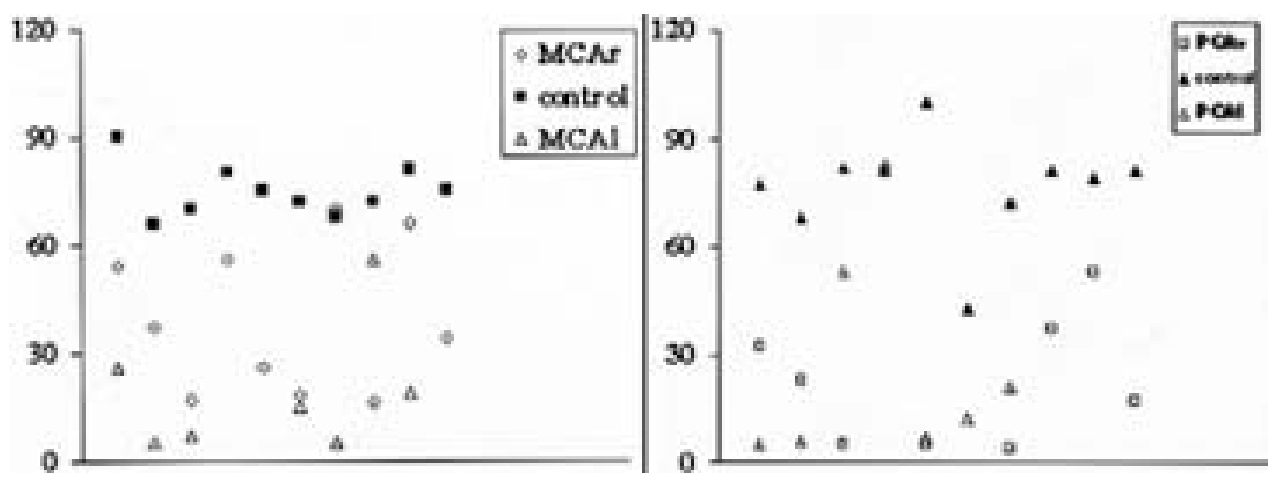

Fig. 6. Scatterplots. Left: Graphic representation of mean values obtained in the MCA (r = right; $1=$ left). Right: Mean values observed in the PCA in 10 Group 1 asymptomatic infants. The values are expressed in percentage of carbon reactivity. The results are compared with those obtained in the control group. 
Some authors evaluated pre- and post-shunt therapy hemodynamic changes and their correlation with the clinical results in normal-pressure hydrocephalus. ${ }^{4,17}$ The vasomotor reactivity documented by TCD ultrasonography with $\mathrm{CO}_{2}$ testing before and after shunt placement demonstrated that shunt treatment improves vasomotor reactivity in responsive patients. Postoperatively, an increase of vasomotor reactivity tends to accompany improvement of the functional status.

Autoregulatory capacity may partly or completely be lost after stroke, cerebrovascular insufficiency, or subarachnoid hemorrhage.${ }^{1,9}$ Cerebral autoregulation is a homeostatic mechanism that minimizes deviations in $\mathrm{CBF}$ when cerebral perfusion pressure changes. ${ }^{11,35}$

Analysis of our results showed that vasomotor reactivity was severely reduced in patients with hydrocephalus and functioning shunts. The autoregulatory capacity may be partly or completely lost after long-term shunt therapy. Some authors have demonstrated that in patients with limited pressure-volume compensatory reserve, there can be an excessive increase in ICP during cardiovascular fluctuations, especially at night; this may cause night-time or early-morning headaches in patients with blood flow-control devices. ${ }^{10}$

The aforementioned functional tests are a noninvasive means by which to assess cerebral compliance and $\mathrm{CO}_{2}$ vasomotor reactivity. The fontanelle compression test has been used to increase intracranial volume transiently and thus help establish a diagnosis of abnormal cranial compliance in infants, and it may be helpful in timing the surgical revision of the shunt. These tests are also helpful for evaluating cerebral autoregulation dynamics in infants with hydrocephalus.

\section{CONCLUSIONS}

Transcranial color-coded Doppler ultrasonography can be used to follow and monitor children with hydrocephalus. It is a useful, noninvasive predictor of elevated ICP and may be helpful in timing or predicting the need for treatment in malfunctioning shunts.

We have evaluated hemodynamic changes by using TCCD ultrasonography in children with hydrocephalus treated using shunt therapy and studied their correlation with functional and dysfunctional shunts. The results of $\mathrm{CO}_{2}$ vasoreactivity test showed that the autoregulatory capacity may be partly or completely lost after long-term shunt therapy.

\section{Acknowledgments}

We thank Drs. Christian Sainte-Rose, Michel Zerah, Hermes Prado, Jr., and Luiz A. Bailao for assistance, critical review, and typing of the manuscript.

\section{References}

1. Aaslid R, Huber P, Nornes H: Evaluation of cerebrovascular spasm with transcranial Doppler ultrasound. J Neurosurg 60: 37-41, 1984

2. Aaslid R, Markwalder TM, Nornes H: Noninvasive transcranial Doppler ultrasound recording of flow velocity in basal cerebral arteries. J Neurosurg 57:769-774, 1982

3. Anderson JC, Mawk JR: Intracranial arterial duplex Doppler waveform analysis in infants. Childs Nerv Syst 4:144-148, 1988

4. Bakker SL, Boon AJ, Wijnhoud AD, et al: Cerebral hemodynamics before and after shunting in normal pressure hydrocephalus. Acta Neurol Scand 106:123-127, 2002

5. Bode H: Pediatric Applications of Transcranial Doppler Sonography. New York: Springer-Verlag, 1988, pp 91-92

6. Bogdahn U, Becker G, Winkler J, et al: Transcranial colorcoded real-time sonography in adults. Stroke 21:1680-1688, 1990

7. Byrd SE, Seibert JJ: Transcranial Doppler imaging in pediatric abnormalities in older children. Neuroimaging Clin N Am 9: 17-40, 1999

8. Chadduck WM, Crabtree HM, Blankenship JB, et al: Transcranial Doppler ultrasonography for the evaluation of shunt malfunction in pediatric patients. Childs Nerv Syst 7:27-30, 1991

9. Cigada M, Marzorati S, Tredici S, et al: Cerebral CO2 vasoreactivity evaluation by transcranial Doppler ultrasound technique: a standardized methodology. Intensive Care Med 26: 729-732, 2000

10. Czosnyka M, Czosnyka Z, Whitehouse H, et al: Hydrodynamic properties of hydrocephalus shunts: United Kingdom Shunt Evaluation Laboratory. J Neurol Neurosurg Psychiatry 62: 43-50, 1997

11. Czosnyka ZH, Czosnyka M, Whitfield PC, et al: Cerebral autoregulation among patients with symptoms of hydrocephalus. Neurosurgery 50:526-533, 2002

12. Drake JM, Sainte-Rose C: The Shunt Book. Cambridge, MA: Blackwell Science, 1995

13. Gosling RG, King DH: Continuous wave ultrasound as an alternative and complement to $\mathrm{x}$-rays in vascular examination, in Reneman RS (ed): Cardiovascular Application of Ultrasound. Amsterdam: North-Holland, 1974, pp 266-282

14. Hanlo PW, Gooskens RH, Nijhuis IJ, et al: Value of transcranial Doppler indices in predicting raised ICP in infantile hydrocephalus. A study with review of the literature. Childs Nerv Syst 11:595-603, 1995

15. Hill A, Volpe JJ: Decrease in pulsatile flow in the anterior cerebral arteries in infantile hydrocephalus. Pediatrics 69:4-7, 1982

16. Kang JK, Lee IW: Long-term follow-up of shunting therapy. Childs Nerv Syst 15:711-717, 1999

17. Lee EJ, Hung YC, Chang CH, et al: Cerebral blood flow velocity and vasomotor reactivity before and after shunting surgery in patients with normal pressure hydrocephalus. Acta Neurochir 140:599-605, 1998

18. Machado HR, Martelli N, Assirati Junior JA, et al: Infantile hydrocephalus: brain sonography as an effective tool for diagnosis and follow-up. Childs Nerv Syst 7:205-210, 1991

19. Nagai H, Moritake K, Takaya M: Correlation between transcranial Doppler ultrasonography and regional cerebral blood flow in experimental intracranial hypertension. Stroke 28:603-608, 1997

20. Norelle A, Fischer AQ, Flannery AM: Transcranial Doppler: a noninvasive method to monitor hydrocephalus. J Child Neurol 4 (Suppl):S87-S90, 1989

21. Pople IK, Quinn MW, Bayston R, et al: The Doppler pulsatility index as a screening test for blocked ventriculo-peritoneal shunts. Eur J Pediatr Surg 1 (Suppl 1):27-29, 1991

22. Pourcelot L: L'examen Doppler des Vaisseaux Périphériques. Paris: ACD Productions, 1980, pp 60-85

23. Rainov NG, Weise JB, Burkert W: Transcranial Doppler sonography in adult hydrocephalic patients. Neurosurg Rev 23: 34-38, 2000

24. Ringelstein BE, Sievers C, Ecken S, et al: Noninvasive assessment of CO2-induced cerebral vasomotor reponse in normal individuals and patients with internal carotid artery occlusions. Stroke 19:963-969, 1988 
25. Rosenberg HK, Sherman NH, Gubernick JA: Pediatric head, in McGahan JP, Goldberg BB (eds): Diagnostic Ultrasound: A Logical Approach. Philadelphia: Lippincott-Raven, 1998, pp 1135-1176

26. Sainte-Rose C, Hooven MD, Hirsch JF: A new approach in the treatment of hydrocephalus. J Neurosurg 66:213-226, 1987

27. Schoning M, Grunert D, Stier B: [Transcranial duplex sonography through intact bone: a new diagnostic procedure.] Ultraschall Med 10:66-71, 1989 (Ger)

28. Schoning M, Niemann G, Hartig B: Transcranial color duplex sonography of basal cerebral arteries: reference data of flow velocities from childhood to adulthood. Neuropediatrics 27: 249-255, 1996

29. Schoser BG, Riemenschneider N, Hansen HC: The impact of raised intracranial pressure on cerebral venous hemodynamics: a prospective venous transcranial Doppler ultrasonography study. J Neurosurgery 91:744-749, 1999

30. Seibert JJ, McCowan TC, Chadduck WM, et al: Duplex pulsed Doppler US versus intracranial pressure in the neonate: clinical and experimental studies. Radiology 171:155-159, 1989

31. Sood S, Ham SD, Canady AI: Current treatment of hydrocephalus. Neurosurgery Quarterly 11:36-44, 2001

32. Taylor GA: Effect of scanning pressure on intracranial hemodynamics during transfontanellar duplex US. Radiology 185: 763-766, 1992
33. Taylor GA: Sonographic assessment of posthemorrhagic ventricular dilatation. Radiol Clin North Am 39:541-551, 2001

34. Taylor GA, Madsen JR: Neonatal hydrocephalus: hemodynamic response to fontanelle compression-correlation with intracranial pressure and need for shunt placement. Radiology 201: 685-689, 1996

35. Valdueza JM, Draganski B, Hoffmann O, et al: Analysis of $\mathrm{CO} 2$ vasomotor reactivity and vessel diameter changes by simultaneous venous and arterial Doppler recordings. Stroke 30: 81-86, 1999

36. Wang HS, Kuo MF, Huang SC, et al: Transcranial ultrasound diagnosis of intracranial lesions in children with headaches. Pediatr Neurol 26:43-46, 2002

37. Westra SJ, Lazareff J, Curran JG, et al: Transcranial Doppler ultrasonography to evaluate need for cerebrospinal fluid drainage in hydrocephalic children. J Ultrasound Med 17: 561-569, 1998

Manuscript received May 7, 2003.

Accepted in final form September 28, 2003.

Address reprint requests to: Helio R. Machado, M.D., Ph.D., Division of Pediatric Neurosurgery, Hospital das Clínicas da Faculdade de Medicina de Ribeirão Preto (USP), Av. Bandeirantes, 3900 CEP: 14049-900, Sao Paulo, Brazil.email: hrmachad@fmrp.usp.br. 